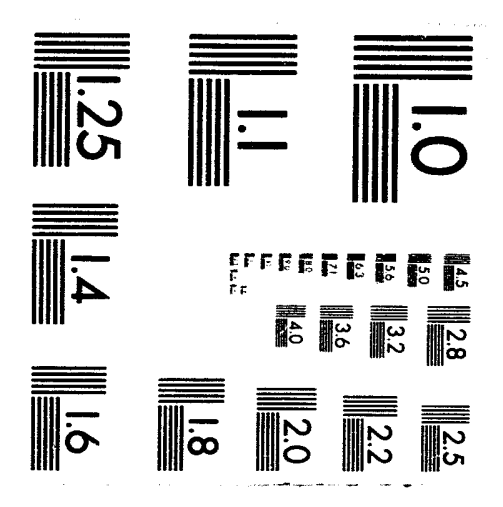



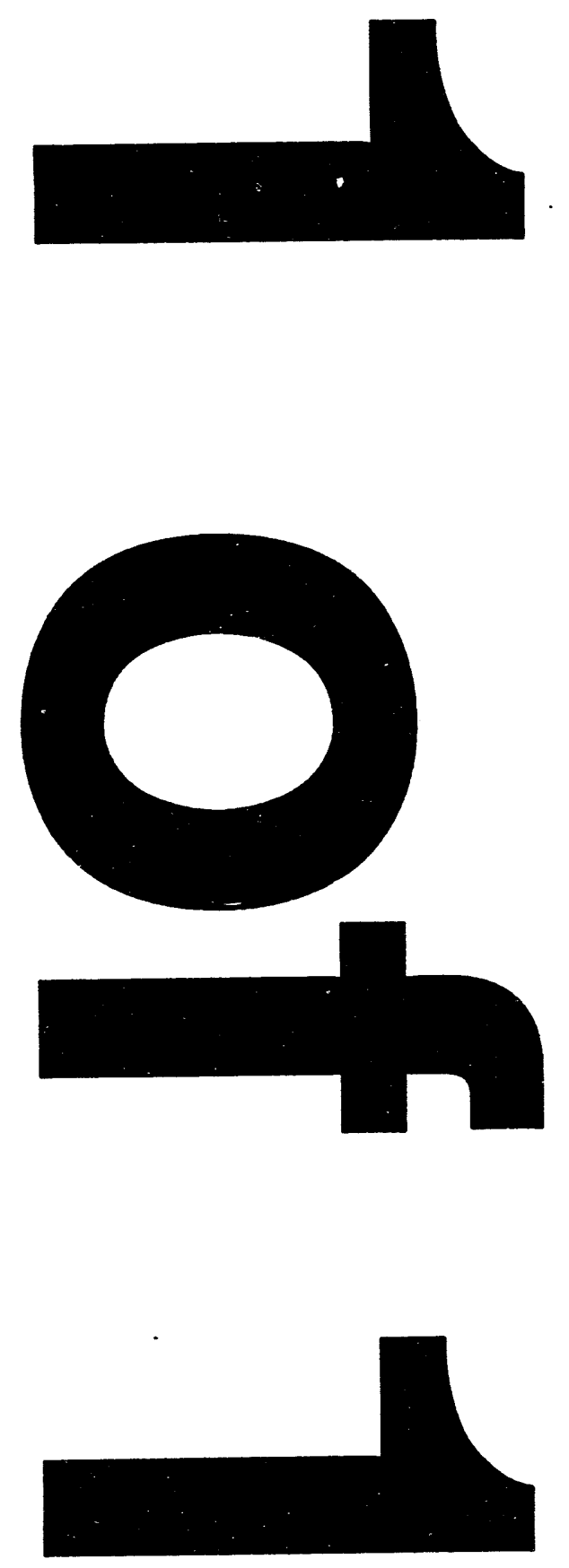
This report was prepared as an account of work sponsored by an agency of the United States Government. Neither the United States Government nor any agency thereof, nor any of their employees, makes any warranty, express or implied, or assumes any legal liability or responsibility for the accuracy, completeness, or usefulness of any information, apparatus, product, or process disclosed, or represents that its use would not infringe privately owned rights. Reference herein to any specific commercial product, process, or service by trade name, trademark, manufacturer, or otherwise does not necessarily constitute or imply its endorsement, recommendation, or favoring by the United States Government or any agency thereof. The views and opinions of authors expressed herein do not necessarily state or reflect those of the United States Government or any agency thereof.

\title{
ENVIRONMENTAL REMEDIATION AND WASTE MANAGEMENT INFORMATION SYSTEMS (SAND93-3987C)
}

\author{
M. W. HARRINGTON and C. P. HARLAN \\ Sandia National Laboratories \\ P. O. Box 5800, MSO743 \\ Albuquerque, NM 87185-5800, USA
}

\section{Introduction}

In recent years, there has been a proliferation of environmental software systems, many of them environmental databases. Accessing an online system or consulting a database is a quick way to gain current information on a substance's toxicity, determine the location of a Superfund Site, or access regulatory requirements. Databases are available online, as well as on CD-ROM, diskettes, and magnetic tape. Databases are becoming more accessible, practical, reliable, and current. For example, cartographic databases are capable of providing geographic information, such as data on roads, streams and lakes, elevations, towns, political boundaries, geologic strata, and population densities. These systems allow for information to be collected, analyzed, and displayed spatially.

The purpose of this paper is to document a few of the many environmental information systems that currently exist worldwide. The paper is not meant to be a comprehensive list; merely a discussion of a few of the more technical environmental database systems that are available. Regulatory databases such as U. S. Environmental Protection Agency's (EPA's) RODS (Records of Decision System) database [EPA, 1993] and cost databases such as EPA's CORA (Cost of Remedial Action) database [EPA, 1993] are not included in this paper.

Section 2 describes several U. S. Department of Energy (DOE) Environmental Restoration and Waste Management (EM) information systems and databases. Section 3 discusses several U. S. EPA information systems on waste sites and technologies. Section 4 summarizes a few of the European Community environmental information systems, networks, and clearinghouses. And finally, Section 5 provides a brief overview of Geographical Information Systems. Section 6 contains the references, and the Appendices contain supporting information.

This work was supnorted by the United

States Depariment of Energy under

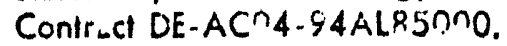

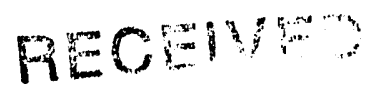

FEB 071994

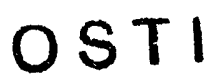




\section{U. S. Department of Energy Environmental Information Systems}

\subsection{EnvirOTRADE INFORMATION SYSTEM}

The EnviroTRADE Information System [ET, 1992] is a graphical/textual information management system being developed for the cleanup program of U.S. Department of Energy's nuclear weapons complex. This system is currently being developed at Sandia National Laboratories (SNL) by the authors of this paper. Therefore, more detailed information is discussed here than in the summaries of the other information systems.

EnviroTRADE's principal purpose is to provide a single, powerful, interactive database on the many environmental restoration and waste management (ER/WM) problems and on the technologies currently under development and available to resolve them. Because of the complexity and potential volume of the information, a sophisticated Relational Database Management System (RDBMS) is employed for EnviroTRADE which accommodates graphical images, technical data, structured textual descriptions, and a variety of coded data. EnviroTRADE is intended to be a multi-purpose, multi-user system capable of addressing a broad range of environmental assessment and cleanup issues. An early focus for the development of the system has been to provide a decision-support tool to find matches between specific environmental problems at particular sites (e.g., in terms of ER/WM activity, waste contaminant, waste composition and form) and available or new technologies which are suited to those problems. Also, Technology owners can find sites where their technology might be applied. Both U.S. and foreign problems and technologies are included in the current prototype EnviroTRADE database.

\subsubsection{EnviroTRADE Prototype System}

The prototype system demonstrates the feasibility of such a multi-purpose system, and provides a testbed for refining the system architecture. A variety of sources have been used to develop the current information base, mostly about DOE's environmental problems and technologies. DOE/EM's 5-year plan and other DOE/EM documents contain information on the DOE's environmental problems and plans for technology development. Technologists at SNL and at other national laboratories have provided the project with information. For example, Dawn Kaback at the Savannah River Site (SRS) provided EnviroTRADE with information on the "VOC's in Non-Arid Soils" Integrated Demonstration (ID) that the Office of Technology Development (OTD) has funded for several years at SRS. Dr. Kaback provided descriptions, brochures, photographs and drawings of the remediation progress and many of the monitoring, characterization, and remediation technologies being applied at the SRS site.

Color brochures on other IDs and technologies have been collected at a variety of conferences and workshops. Private sector technologies have also been collected at these conferences, and private technology owners frequently mail their corporate brochures voluntarily to SNL in hopes of having their technologies represented in the EnviroTRADE Information System. A formal process is currently underway to capture OTD's technologies in EnviroTRADE at the same time that they are being documented in EM-521's "Catalogue of OTD Technologies". 
Foreign information has primarily been extracted from reports developed under EM-523's international country surveys and Pacific Northwest Laboratory's (PNL's) Nuclear Fuel Cycle Fact Book.

There are currently a variety of EM waste sites ("needs") entered into the system. All have profiles of varying length describing the site problem and EM activity that is desired to be resolved or addressed by technologies. When photographs or graphical images are available, they are displayed alongside the profile. Most of the Prototype's waste sites are U.S. DOE's primary ER and WM priorities, and a few represent waste site problems in foreign countries. The Prototype information represents waste sites that require remediation, characterization, monitoring, minimization, treatment, and disposal. Appendix A and Appendix B contain example waste site profiles.

There are currently a wide variety of technologies in the Prototype System - both technologies in the R\&D phase and those being tested and/or currently available. Most of the technologies are from the U.S. national laboratory projects, a few are from the U.S. private sector, and some are representative of technologies found in foreign countries (Japan, Germany, Poland, Hungary, Ukraine, and the United Kingdom). Appendices C, D, and E contain example technology profiles.

Pacific Northwest Laboratories (PNL) was funded in DOE's fiscal year 1992 to provide the EnviroTRADE Project with an electronic version of its International Nuclear Fuel Cycle Fact Book, Version 12. EnviroTRADE contains general country information on the 23 countries in the Fact Book, plus additional country profiles on Poland and Hungary.

A Geographical Information System (GIS) capability has been imbedded into the EnviroTRADE System. When "views" or spatial data files are available, an ArcView button is available for viewing the information. ArcView is an inexpensive read-only window on the views that have been developed using the ArcInfo GIS software toolbox. These GIS software tools are being developed, maintained, and distributed by Environmental Science Research Institute (ESRI), a private software company based in Redlands, California. The Prototype contains three demonstration GIS views on Poland, northern Russia (Arctic contamination), and a U.S. basemap. A duplicate system resides in DOE/EM's office in Germantown, Maryland. The Arctic GIS has also been provided as a standalone PC demonstration. Since many environmental sites (including many of the DOE's) are collecting and managing environmental information in GIS systems, it is expected that the full EnviroTRADE System will use this capability to absorb and display site-specific information that has already been collected in detail about the various sites. The site-specific views merely need to be hooked up to the site profiles in the database.

The prototype database schema is made up of the 14 tables and the relationships in the tables, that form the structure for storing the coded information required for the system. The coded information contains the necessary underlying attributes to support the storing and retrieval of profiles and graphics about the sites and the technologies. For example, the matching algorithm requires information for both sites and technologies concerning the EM activity (monitoring, characterization, in-situ remediation, extraction, treatment, disposal, etc.), the contaminant or contaminants of concern, and the media or form of the waste involved. These attributes can be used to match appropriate site problems with technologies. 


\subsubsection{Expansion of EnviroTRADE}

As the architecture and database grow, an increasing range of applications which EnviroTRADE can address is envisioned. Of particular importance is the need to import very large quantities of graphical, textual, and numerical information in to the database. Fortunately, a great deal of appropriate data already exists in various electronic formats. It is SNL's intention to cooperate with these efforts, where possible, to quickly populate the EnviroTRADE system with meaningful data. Some of the information can be imported directly into the EnviroTRADE structure. In other cases, intelligent gateways may be established that can interact with other systems - either by selecting certain information from the partner database for displaying in the EnviroTRADE application, or by remotely logging into the partner database allowing the user to run the partner's native user interface. Gateways have the advantage of allowing for access and sharing of current information maintained by another system, thereby eliminating duplication of data collection and quality efforts.

A major effort and important component of the overall long-term success of the full EnviroTRADE system is the commitment to the stewardship of the information base. Stewardship includes continued review and improvement of the information, tracking of data quality (pedigree, lineage), configuration control, and database administration. To keep the EnviroTRADE Information System viable, attention must be paid to frequency and quality of data updates, upgrades to the RDBMS over time, and database administration.

\section{$2.2 \mathrm{RAAS} / \mathrm{ReOpt}$}

The RAAS (Remedial Action Assessment System) [RAAS, 1992] database is under development for the DOE/EM by Pacific Northwest Laboratories (PNL) and contains technical information on environmental restoration technologies. These technology descriptions are generic, and do not provide vendor information. ReOpt is the commercialized version of RAAS. Searches are allowed by media, contaminant, and the way the user wants to restore the site. Each technology contains the following information:

(1) flow diagram

(2) description

(3) engineering or design parameters

(4) contaminant applicability

(5) data requirements

(6) associated technologies

(7) technical constraints

(8) regulatory constraints

(9) references

(10) previous applications

The system information is structured around 88 remediation technologies, eight technology functions, ten media types, and 399 specific contaminants. RAAS/ReOpt runs on a Macintosh II with a high resolution color monitor and on PCs. The system requires the use of ORACLE database software, and is available on diskette for Federal government users and their contractors from the Energy Science and Technology Software Center (ESTSC). 


\subsection{ProTech}

The DOE's Office of Technology Development (EM-55) is funding the Prospective Technology (ProTech) computer-based communication tool that is currently a prototype system. The system is designed to describe the technologies designated for DOE's Integrated Demonstrations (IDs). The current audience targeted to use ProTech includes non-technical but informed stakeholders and the general public who may be interested in DOE's IDs such as the Volatile Organic Compound (VOCs) IDs at Hanford, Washington. There are currently six IDs depicted in the system.

ProTech is a prototype system that divides all technologies into five categories: drilling, characterization and monitoring, extraction, above-ground treatment, and in-situ destruction or containment of contaminants. Profiles contain information on performance, cost, cleanup time, ease of use, regulatory acceptance, public acceptability, etc. The user can click on any technology to pull up a fact sheet of information about the technology.

ProTech operates on a Macintosh computer platform and describes the technologies through computer screens. For more information, contact Bill Noel., U.S. DOE, 301-903-7900, or Ann Lesperance, PNL, 206-528-3223.

\subsection{DOE/OTD's Technology Catalogue}

DOE's Office of Technology Development (OTD, EM-50) has the responsibility for developing and testing environmental technologies for DOE's Office of Waste Management (EM-30) and DOE's Office of Environmental Restoration (EM-40). The technology needs are identified through reviews of environmental requirements at the DOE's laboratories and other sites. OTD tests the developing technologies through Integrated Demonstrations (IDs) and Integrated Programs (IPs). The IDs test and evaluate systems, consisting of coupled technologies, at specific sites to address generic problems. The IPs support applied research activities in specific applications areas.

The Technology Integration Division EM-521 has undertaken the responsibility of documenting performance data for the technologies under development for DOE/EM. During DOE's fiscal year 1993, a "Technology Catalogue" was published [Catalogue, 1993]. This Technology Catalogue features 44 technologies successfully demonstrated in the field through IDs and sufficiently mature to use in the near-term. Technologies on characterization, monitoring, and remediation are included and were tested at one of the 5 following IDs:

(1) Buried Waste ID (INEL)

(2) Mixed Waste Landfill ID (SNL)

(3) Underground Storage Tank ID (Hanford, WA)

(4) Volatile Organic Compound (VOC) Arid ID (Hanford, WA)

(5) VOC-Non Arid ID (SRS)

The files of information are contained in paragraph form, and no coded attributes or key words are included. The type of information collected includes technical description of the technology, 
performance data, waste applicability, status, 1 egulatory considerations, potential commercial applications, baseline technology, intellectual property rights, and contacts.

Although this project produces a hardcopy (notebook) of information, an electronic copy of the technology profiles has also been submitted to the EnviroTRADE project for inclusion in its database. The "Catalogue" project, now and as it expands its information base, is considered a good source of DOE/OTD technology information for EnviroTRADE, also funded by EM-50.

\subsection{Technology Needs Crosswalk}

The Technology Needs Crosswalk project was conducted for DOE/EM by Chem- Nuclear Geotech, Inc., Grand Junction, Colorado [Crosswalk, 1993]. The purpose of the project was to collect and categorize EM's worst remediation problems and then identify areas where technologies are lacking. Data was collected from field and site personnel and entered into the Crosswalk database. Keywords were assigned to each worksheet to facilitate the matching of problems (ex: media, contaminant, physical setting, type of remediation activity required). The site descriptions include schedule requirements, performance goals, and contacts.

Technologies were also assigned keywords that categorize their function. Matches can then be made between environmental problems and technologies. Gaps in technology needs can also be identified.

Although this project was primarily meant to be a study to improve DOE/EM-50's technology development response to DOE/EM-40's needs, a large amount of information on DOE's needs and technology development efforts has also been entered into a database.

\subsection{WMIS}

The Waste Management Information System (WMIS) database developed for the DOE is being developed as a waste management planning tool. The system contains information on waste streams and treatment, storage, and disposal facilities throughout the DOE complex. It is currently populated with mixed, hazardous, and radioactive waste data from the various DOE sites.

The data exists in two primary areas: (1) treatment, storage, and disposal (T/S/D) capabilities a compilation of DOE facilities for treatment/storage/disposal of waste., and (2) waste profiles data on the various waste streams that have been identified for waste management activities. Data includes generation rates, quantities, characterization, contacts, and applicable waste management options. For more information, contact Lise Wachter, HAZWRAP, Martin Marietta Energy Systems, P.O. Box 2003, MS-7606, Oak Ridge, TN 37831-7606, 616-435-3281.

\subsection{Chemical Contaminants at DOE Sites}

A hardcopy report was developed in 1992 that documents the chemical contaminants on DOE lands [Chemical, 1992]. The report identifies individual contaminants and contaminant mixtures that have been measured in the soils and groundwater at 91 waste sites at 18 U.S. DOE facilities. 
Use of generic mixtures will focus research on important mixed contaminants that are likely to be long-term problems at DOE sites and that will require cleanup or remediation.

The 77-page report contains summary tables that document the frequency of occurrence at DOE facilities of the most commonly reported mixtures of chemicals in soils and groundwater.

For more information on this document, contact Dr. John Zachara, Geosciences Department, Pacific Northwest laboratory, P.O. Box 999, Richland, WA 99352.

\subsection{Technology Logic Diagram (TLD)}

The purpose of the Technology Logic Diagram (TLD) is to provide a planning document for DOE, DOE operating contractors, and private industry that relates the ER/WM problems at DOE sites. The first TLD was developed for the Oak Ridge K-25 Site with technologies that can be used to remediate these problems. In doing so, the status of each potential remediation technology is evaluated. Several important aspects impacting implementation of each technology are folded into the evaluation in a way that the appropriateness of each technology can be evaluated. These aspects are (1) potential effectiveness of the technology (how successful when applied at a site), (2) level of maturity of the technology (when can it be applied to site problems), and (3) level of waste management required for the technology (what wastes are generated as a result of the use of the technology). The TLD addresses the enforceable compliance and cleanup agreements that have designated timetables for ameliorating the specific site problems. For potentially attractive but immature technologies, or those that improvement paths (which make them faster, better, safer, and cheaper) are visualized, priorities can then be assigned to technology development activities.

The formulation of the K-25 Site Technology Logic Diagram (TLD) was led by personnel from the K-25 Program Management Organization and the K-25 Technical Division, with participation from across Martin Marietta Energy Systems, Inc. Although a number of K-25 Site personnel were involved, approximately half of the team was selected from other Energy Systems organizations in Oak Ridge, such as the Y-12 Plant, Central Engineering, and Oak Ridge National Laboratory. The personnel from these organizations represent input from personnel associated with programs under the Department of Energy (DOE) Deputy Assistant Secretaries of Waste Management (EM-30), Environmental Restoration (EM-40) and Technology Development (EM50).

\subsection{WMTAD}

DOE/EM-50 and Los Alamos National Laboratory (LANL) are developing an electronic data system to identify, track, organize, and maintain information on wastes and technologies appropriate for use at DOE sites. The system is called the Waste Management and Technologies Analysis Databases (WMTAD). This information will assist the DOE, field sites, and regulatory agencies with their waste management efforts. For additional information, contact Bill McCulla, LANL, 505-667-2148. 


\section{U.S. Environmental Protection Agency Environmental Information Systems}

\subsection{VISITT 2.0}

VISITT (Vendor Information System for Innovative Treatment Technologies) [VISITT, 1993] was developed by the Technology Innovation Office (TIO) of the U.S. Environmental Protection Agency (EPA) Office of Solid Waste and Emergency Response (OSWER). The purpose for this software is to provide private, state, and federal professionals with a means of obtaining up-todate information on current technologies for innovative treatments to be used in the remediation of contaminated sites. The database provides a platform for users to view current technologies; query the database for information on specific technologies, vendors, technology comparisons, or the appropriateness of certain technologies for specific contamination problems.

VISITT Version 2.0 has been updated from the 1992 Version 1.0, to contain information on approximately 230 technologies and 140 vendors. Two hotline phone numbers are provided for help: 800-245-4505 and 703-883-8448.

A technology in the VISITT database is defined to have sufficient performance and cost data available so that it can be considered for routine use for contaminated site clean up. The lack of such information excludes the inclusion of the technology from the database. Technologies address the treatment of: soil, sludge, solids, and natural sediments, found above ground and in place. Also, methods of treating ground water in situ and the treatment of off-gas generated by the innovative treatment systems are included in VISITT.

Only innovative technologies are considered, therefore, more established technologies pertaining to: incineration, solidification-stabilization, methods of treating aqueous waste above ground, containment technologies, technologies that treat routinely generated industrial wastes, and technologies that measure and monitor wastes, are not included in the VISITT database.

\subsubsection{The Vendor Record}

All the information for VISITT database was obtain by the EPA using their Vendor Information Form 2.0 (EPA Form 540/2-91/011 Number 2) and was submitted by the individual vendors. The Vendor Information Form 2.0 is represented in the VISITT database as the Vendor Information Record. Each of these records contains only the information which the vendor wants represented in the database. This information is presented in two main sections: General Vendor Information and Other Information Options.

\subsubsection{General Vendor Information}

This section contains information pertaining to the specific technology (name, type, status), and general vendor information (name, address, contact). It also specifies if the vendor is participating in the EPA's Superfund Innovative Technology Evaluation program (SITE).

\subsubsection{Other Information Options}

This section contain all the available information about each technology broken down into categories which can be used to create user specified queries. These categories are as follows:
1. Description
7. Representative Projects 
2. Highlights

3. Limitations

4. Other Comments

5. Waste Applications

6. Summary of Performance
8. Estimated Price Range

9. Available References

10. Bench-Scale Information

11. Pilot-Scale Information

12. Full-Scale Information

\subsubsection{Search Criteria}

Search categories in VISITT are displayed horizontally across the top of the screen allowing the user to select from four primary search categories: Waste, Technology, Vendor, and Site. After selecting a primary search category, the user can select one of the four basic search operations (Select Search Criteria, Perform Search, Clear Search Criteria, and Print). A query is set up by selecting the "Select Search Criteria" operation. This operation displays a sub-menu of Search Criterion for the initially selected primary search category. A selection of a Search Criterion asks whether to show "Potentially Could Be Treated" or "Actually Treated" values from the vendor information. After selecting on the Potentially / Actually Treated values, a look-up table of Search Values is opened. Multiple search values can be selected from the look-up table to tailor the query to individual needs. This allows the information used in the search to be very broad based or narrow depending on specific requirements. Selection Logic can be added to allow for searches from many different Search Criterion and Look-up tables.

After performing the search on the query, a list of vendor / technologies is displayed to the screen. From the vendor / technology list, the user can either go to printing options or select individual vendors and technologies for more in-depth information. Selecting a vendor / technology allows you to either view the "General Vender Information" for the vendor or the "Other Information Options" for the technology as described above.

\subsection{ATTIC}

EPA's ATTIC (Alternative Treatment Technology Information Center) [ATTIC, 1991] database contains abstracts on a large number (over 2000) of hazardous waste cleanup technologies. It can be accessed through an electronic bulletin board with a PC and modem 24 hours a day. The system maintains two phone numbers: 301-670-6294 for a system operator and 301-670-3808 for computer access. In addition, information is provided on technical contacts and upcoming conferences and events.

The system contains technology information on biological treatment, chemical treatment, solidification/stabilization, and thermal treatment. The user can access abstracts that highlight a description of the treatment technology, media, contaminant, performance and cost data, quality of data, and contacts. By calling the hotline, searches can be run for the user, and assistance given to construct your own search criteria.

Once specific abstracts are identified, full-text copies of the source documents can be obtained from: (1) NTIS (the National Technical Information Service), (2) EPA's Center for Environmental Research Information, and (3) requesting that ATTIC staff FAX or mail documents to you (free to federal, state, and local governments). 


\subsection{CLU-IN}

The Cleanup Information Bulletin Board System (CLU-IN) [EPA, 1993] is designed for hazardous waste cleanup professionals to use in finding current events information about innovative technologies, consulting with one another online, and accessing databases. CLU-IN is used by those involved in the cleanup of Superfund, Resource Conservation and Recovery Act (RCRA) corrective action, and underground storage tank sites, including EPA staff, other Federal and State personnel, consulting engineers, technology vendors, remediation contractors, researchers, community groups, and the public.

Electronic messages can be directed to single users or large audiences. Bulletins can be read online such as summaries of Commerce Business Daily and Federal Register notices on hazardous waste, descriptions and listings of EPA documents, etc. Also, online databases can be searched by CLU-IN.

Access to CLU-IN through a modem connection by dialing 301-589-8366. For more information, contact the CLU-IN Systern Operator at Tel: 301-589-8368 or Fax: 301-589-8487.

\subsection{NETAC}

The National Environmental Technology Applications Corporation (NETAC), a subsidiary of the University of Pittsburgh Trust, is funded primarily by EPA to evaluate and document environmental technologies. NETAC was created in 1988 to offer a variety of services to help environmental technology developers bring new technologies to national and international markets. Some of the innovative technologies are being developed by the national laboratories.

The NETAC database contains profiles on approximately 2000 technologies. Users do not interact with the database directly, but instead outline their particular area of interest for NETAC staff who develop a report containing the appropriate information. Technology profiles are organized by the media treated, contaminant, and technology categories. The profiles also contain information on regulatory analyses, environmental training, country-specific environmental industry, and market penetration strategies.

\subsection{CRES and PRP Superfund Sites}

The CERCLIS Remedial Event Schedule (CRES) database and the Potentially Responsible Party (PRP) database were prepared by Pasha Publications as adjuncts to the 92-93 Guide to Superfund Sites. Both the CRES and PRP databases are offered in standard DBF format, which is compatible with other database and spreadsheet formats.

CRES contains data from the SCAP11 Report that is publicly available from EPA. Each of the 3,152 records represents an event currently under way or scheduled to begin in the future at Superfund Sites. The PRP database is based on the SETS database marketed by EPA via the National Technical Information System. Each of the 20,235 records contains names of potentially responsible parties associated with specific sites. Both databases are copyrighted. For more information, contact Pasha Publications, Inc., 1616 North Fort Myer Dr., Suite 1000, Arlington, VA 22209. 


\section{International Fnvironmental Information Systems}

International networks, clearinghouses, and cooperative efforts exist to share information on environmental issues. Particularly in Central and Eastern Europe, existing systems and opportunities for future systems are unfolding.

The DOE/EM proposes to establish EnviroTRADE nodes in strategic locations that will serve environmental information over local area networks (LANs) and wide area networks (WANs) [INTN, 1992]. The EnviroTRADE Information System is designed to maintain and present information on environmental problems and technologies worldwide. The primary communication system being considered is the on-line service of the Internet which currently contains about 700 networks and 60,000 host computers making it the most widely used international network communication service. Internet is a collection of regional networks that are connected to each other by the national Science foundation Network (NSFNET) whose purpose is to support research and the opportunity for collaborative work.

One proposed node for the EnviroTRADE system in a strategically-located area of Europe is the Technical University of Budapest (TUB) located in Budapest, Hungary. The TUB has been involved with conducting environmental research for more than ten years in Hungary and works cooperatively with the Regional Environmental Center (REC) for Central and Eastern Europe which is also located in Budapest. The REC is an independent, not-for-profit, non-governmental organization whose mission is to develop and support environmental organizations and initiatives in order to foster sustained economic growth in the region's newly emerging democracies. REC Clearinghouse functions are carried out to match needs with resources such as assistance programs, exchange programs, fellowships, technical experts, and equipment.

An additional EnviroTRADE node might be placed at the Commission of the European Communities' Joint Research Center (JRC). The JRC has access to a variety of information systems currently maintained within the European Community (EC). One such system is the Community Research and Development Information Service (CORDIS) which provides easy access to large quantities of EC documents on research projects and funding sources. The Central European Environmental Data Request Facility (CEDAR) in Vienna, Austria is a major part of the REC information network. It functions as a computerized gateway between East and West, helping advance environmental technology by providing information to researchers, advanced computer and software systems to regional partners, and electronic sharing of ideas.

Another information system that has been developed focusing on the state of the environment in the European Community is CORINE (Co-ORdinated INformation on the Environment in the European Community) [CORINE, 1988]. This system is an experimental program of the Commission of the European Communities which coordinates the collection of information and data on the condition of the environment throughout the European Communities. The system will be developed so that the environmental information is integrated with a Geographical Information System (GIS). The system was authorized by Decision of the Council of Ministers (Council Decision, 1985). The long term objective of the program is to develop an infrastructure for collecting, maintaining, interpreting, and manipulating environmental information to meet the needs of environmental management in coordinated manner throughout the European Cominunity. 
The United Nations Environment Program (UNEP) initialized the formation of the Global Resource Information Database (GRID) in Warsaw, Poland with support partially provided by Norway. Particular attention is given to satellite information processing technology, telecommunications, resource management, and Geographic Information Systems (GIS) that manage, analyze, and display spatial information. The purpose of GRID is to bring together the disparate datasets to a common geographic base and provide geo-referenced integrated environmental datasets to the scientific community and others. GIS information in the GRID system provides a distinct advantage for an information system such as EnviroTRADE to be used as an international environmental information system.

The environment is of growing concern and interest, both in the U.S. and abroad. Environmental problems do not honor borders, and countries are forming alliances to deal with these problems. A good source of international environmental information is Pira's International Environmental Information Sources [PIRA, 1990].

\section{Environmental Geographic Information Systems (GIS)}

The use of Geographical Information Systems (GIS) grew dramatically in the 1980s and early 1990s from obscurity to becoming commonplace in scientific, academic, government and business applications. GIS's are an organized collection of computer hardware, software, geographical data, and personnel designed to efficiently capture, store, update, manipulate, analyze, and display all forms of geographically referenced information [GIS, 1990].

Traditional relational database information can be maintained about spacial points, lines, and polygons on maps. Points might represent cities, lines could represent roads and rivers, and polygons used to delineate features such as state boundaries or lakes. Thematic layers or coverages can be placed on top of one another and boolean logic employed to answer questions such as "where can I site a landfill that will be in dry soils, near a major access road, with access to power, having a low population density and no surface water." The result of the analysis can be presented and saved as a new coverage. Therefore, GIS can be thought of as a higher-order map.

The DOE/EM is collecting large amounts of environmental information at most of its facilities where contaminated sites must be remediated. In many cases, this information is being collected and analyzed using GIS software tools. It is anticipated that much of this information can be pulled into the EnviroTRADE system as additional "views" of contaminated sites.

During 1993, Golder Associates Inc. conducted a survey of European GIS databases for the EnviroTRADE project [Golder, 1993]. The purpose of this survey was to provide a preliminary assessment of the status of environmental GISs in Europe, identify appropriate contacts and organizations that disseminate this type of data, and an estimate of the level of effort involved in transferring this data into EnviroTRADE. The results of this survey are currently being reviewed. 


\section{REFERENCES}

ATTIC, 1991. EPA Alternative Treatment Technology Information Center (ATTIC), EPA/600/M-91/049.

Catalogue, 1993. Technology Catalogue, Applied Sciences Laboratory, Inc. and Sandia National Laboratories for the DOE, Albuquerque, NM.

Chemical, 1992. Chemical Contaminants on DOE Lands and Selection of Contaminant Mixtures for subsurface Science Research, R. G. Riley and J. M. Zachara, Pacific Northwest Laboratories, DOE/ER-0547T.

CORINE, 1988. Building Databases for Global Science; CORINE: An Information System on the State of the Environment in the European Community, pp. 378, Proceedings from first International Geographical Union Global Database Planning Project, Hampshire, UK.

Crosswalk, 1993]. Technology Needs Crosswalk Report, First Edition, Three Volumes, ChemNuclear Geotech, Inc. for the Department of Energy, DOE/ID/12584-177 Ed. I. GJPO-109.

EPA, 1993, Draft. Accessing Federal Data Bases for Contaminated Site Clean-up Technologies, Environmental Protection Agency, EPA/542/xxx/xxx (Draft), Third Edition.

ET, 1992. EnviroTRADE: An Information System for Providing Data on Environmental Technologies and Needs Worldwide, presented at Eurocourse: Technologies for Environmental Cleanup - Soil and Groundwater, Ispra, Italy, SAND92-1525C, M. W. Harrington and C. P. Harlan, Sandia National Laboratories.

GIS, 1990. Understanding GIS - The ARC/INFO Method, Environmental Systems Research Institute, Inc., Redlands, CA.

Golder, 1993. Survey of European GIS Databases, Golder Associates Inc., Seattle, WA.

INTN, 1992. Overview of Regional and International Networks and Clearinghouses, presented at: International Symposium on Environmental Contamination in Central and Eastern Europe, $S$. W. Johnson, C. M. Pastel, and M. W. Harrington, Budapest'92.

Pira, 1990. Pira's International Environmental Information Sources, Susan Farrell, Pira Information Centre.

RAAS, 1992. Expert Software that Matches Remediation Site and Strategy, K. A. Pennock, S. J. Bohn, and M. K. White, Pacific Northwest Laboratory, Richland, WA.

VISITT, 1993. EPA VISITT - Vendor Information System for Innovative Treatment Technologies, User Manual (VISITT Version 2.0), EPA 542-R-93-001. 


\section{Appendix A - Example Waste Site from EnviroTRADE Chemical Waste Landfill at SNL [ET, 1992]}

Chemical Waste Landfill - US DOE Integrated Demonstration (ID)

ER Remediation of VOC (TCE) in Saturated Soil

ER Remediation of Metal (Chromium) in Unsaturated Soil

Sandia National Laboratories

Albuquerque, New Mexico

\section{DESCRIPTION OF LANDFILL:}

Approximately 1.9 acres

Soil is alluvial deposits, mostly unconsolidated sand, silt, clay, and caliche layers

Low moisture content ( 2 to $8 \%$ )

480 feet to groundwater

Recharge rate approximately $10 . e-8$ to $10 . e-9 \mathrm{~cm} / \mathrm{sec}$

Small gradients $(.005 \mathrm{ft} / \mathrm{ft})$

4 miles to a production well

Waste was dumped in 65 to 70 small unlined pits and trenches

Trenches were typically 10 by 30 feet and 10 feet deep

Uncertainty as to location of all disposal cells, waste segregation, waste types, and waste volumes.

Precipitation $8 " / y r$, pan evaporation $60 " / y r$, low humidity (annual average $46 \%$ ), moderate temperatures normally 23 to 91 deg.F

\section{CONTAMINANTS:}

Primary contaminants are acids, reducers, oxidizers, organics, reactives, and metals. A geophysical survey has been carried out to characterize the subsurface "hot spots." The landfill also contains a chromium pit. Chromium has migrated to a depth of 75 feet in the vadose zone. TCE has been detected in the saturated zone at maximum concentration of $23 \mathrm{ppb}$, migration most likely in the gas phase.

\section{ACTIVITY NEEDED AT THE LANDFILL:}

The environmental activity required is in-situ remediation of VOCs (TCE) in the groundwater and metals (chromium) in the unsaturated soil. The U.S. DOE has chosen this environmental problem for an experimental project as part if its integrated demonstration (ID) program.

\section{INFRASTRUCTURE:}

The site is on Kirtland Air Force Base approximately 6 miles from Interstate 40 accessible by 5.5 miles of paved roads and 0.5 miles of dirt roads. Four groundwater monitoring wells are installed at the site. Three phase electric power is available at the site. Water must be trucked in for two miles. Temporary buildings will be available for small storage and meetings. Emergency response services are available.

\section{TECHNICAL CONTACTS:}

James M. Phelan, Sandia National Laboratories, Department 6621

P.O. Box 5800, Albuquerque, NM 87185-5800

Phone (505) 845-9892, FAX (505) 844-8170 


\section{Appendix B - Example Waste Site from EnviroTRADE VOCs in Soils at SRS [ET, 1992]}

VOCs in Saturated Soil - US DOE Integrated Demonstration (ID)

ER Remediation of VOCs (TCE) in Saturated Soil

Savannah River Site

Aiken, South Carolina, US

DESCRIPTION OF SITE:

The test site is approximately 200 by 300 feet. A groundwater contaminant. The plume is approximately one square mile in size. The contaminant is VOCs in the form of trichloroethylene and tetrachloroethylene (TCE). The problem was created by leakage from a sewer line that carried wastes to a seepage basin operated between 1958 and 1985 . The sewer line acted as a source of VOCs and is known to have leaked at numerous locations along its length. A traditional groundwater extraction and treatment system has been in operation since 1984 and has removed approximately 230,000 pounds of solvents. However, solvents have continued to leach into the groundwater from the vadose zone.

\section{SITE GEOLOGY:}

The site is underlain by a thick wedge of unconsolidated Tertiary and Cretaceous sediments approximately 1000 feet thick. The water table is at a depth of approximately 135 feet. The groundwater in the vicinity of the sewer line contains elevated concentrations of the solvents to a depth greater than $\mathbf{1 8 0}$ feet, within the local Tertiary aquifer.

Vertical groundwater and sediment sampling has been carried out simply from bore holes that were grouted after sampling to eliminate a conduit for contaminant migration. Then permanent monitoring wells were strategically located. Vertical depth sampling provided a quick and cost effective method for characterizing the clay zones and contaminant plumes.

\section{TECHNOLOGY NEEDS:}

In situ remediation technology that uses horizontal wells as delivery and extraction systems in groundwater and soils. The U.S. DOE has chosen this environmental problem for an experimental project as part if its integrated demonstration (ID) program. The in situ technologies have the potential to significantly reduce costs for environmental remedial activities.

\section{TECHNICAL CONTACT:}

John L. Steele

Waste Environmental Remediation Programs

Westinghouse Savannah River Company

Savannah River Site

SRL, 773 A, A208

Aiken, SC 29802

Phone: (803) 725-1830

FAX (803) 725-1660 


\title{
Appendix C - Example Technology from EnviroTRADE Electrokinetic Technology [ET, 1993]
}

\author{
Electrokinetics (Electromigration) \\ Available Technology \\ ER Remediation of Metals in Unsaturated Soil \\ Sandia National Laboratories \\ Albuquerque, New Mexico
}

\section{TECHNOLOGY APPLICATION:}

Remediates in situ heavy metals from partially saturated soils without disturbing the soil. The process, called electrokinetic remediation, uses electrodes implanted in the ground to induce a metal-attracting electric field. Demonstrations at Sandia National Laboratories have shown that this technology can remediate partially saturated soil polluted with chromate ions.

\section{DESCRIPTION OF TECHNOLOGY:}

Electrokinetic remediation of contaminated soil has been demonstrated for saturated and unsaturated sand in preliminary experiments using a novel transport visualization technique. Large anionic organic dyes were mixed with a portion of soil and the rate of electromigration of the dye in an imposed electric field was monitored photographically. One of the fastest current-normalized electromigration rates was measured in the driest sand, which contained $7 \%$ water by weight. This moisture content is typical of the moisture content in the unsaturated zone of subsurface native soils found in New Mexico.

The characteristics of the electromigration were similar in both the saturated and unsaturated sand. The leading edge of the dye migration front was diffuse while the trailing edge was sharp and concentrated. This and other observed behavior may indicate a concentration effect, where the electromigration rate of dilute dye is greater than that of concentrated dye. The soil left after the trailing edge passed seemed to contain no residual dye in both the saturated and unsaturated cases.

The success of demonstrating electromigration of large molecules in unsaturated soil is encouraging and indicates that it may be feasible to remediate in situ anionic heavy metals such as chromate from unsaturated soil with electrokinetic techniques.

\section{TECHNICAL CONTACTS:}

Eric R. Lindgren

Sandia National Laboratories

Albuquerque, NM 87185-5800

Tel: (505) 844-3820

FAX: (505) 844-1480
Earl D. Mattson, SAT-UNSAT Inc.

12004 Del Rey, NE

Albuquerque, NM 87122

Tel: (505) 844-0950

FAX: (505) 844-1480

Matthew W. Kozak, Sandia National Laboratories

Albuquerque, NM 87185-5800

Phone (505) 844-6645, FAX (505) 844-8719 


\title{
Appendix D - Example Technology from EnviroTRADE Horizontal Air Stripping Technology [ET, 1993]
}

\author{
In-Situ Air Stripping (ISAS) of VOCs Using Horizontal Wells \\ ER Remediation of VOCs in Sat/Usat Soils \\ Available \\ Westinghouse Savannah River Company \\ Aiken, SC, U.S.
}

\section{DESCRIPTION:}

In-situ air stripping (ISAS) is a mass transfer process which utilizes horizontal injection and vacuum extraction wells to remediate sites contaminated with volatile organic compounds (VOCs) within the vadose zone and soil/groundwater in the saturated zone. Air is injected into the saturated zone via horizontal injection wells placed below the water table. As the air passes through the contaminant plume it volatilizes the chemical constituents. The amount of volatilization and movement of the solute mass into the air stream is a function of the contaminant concentration, temperature, pressure, and Henry's Law constant of the particular solute. Vapors are collected by upper horizontal gas extraction wells. The extracted air stream is then processed to remove or destroy the liquid and vapor toxic chemicals.

SAS performs best in homogeneous soil conditions, while heterogeneities such as formations, fractures, clay layers, and partial clay lenses hinder performance. Clay layers often have high contaminant concentrations, while stratigraphy can cause preferential flow paths and limit the process efficiency. ISAS has been shown to be effective when some inter-bedded thin and/or discontinuous clays are present.

\section{TECHNICAL PERFORMANCE DATA:}

A field demonstration of ISAS was conducted during fiscal year 1990 at the Savannah River Site (SRS). The site featured a pre-existing line source of soil and groundwater based contamination. The soil geology consisted of interbedded soils, silts and clays, with sands predominating. Vertical-well groundwater and sediment sampling was used to collect multiple samples at various depths. Biomolecular probes were used for laboratory characterization of soil microorganisms. The soil and groundwater of the site have naturally occurring organisms which degrade toxic organic chemicals. Biological monitoring has shown that some contaminant-degrading organisms have flourished at the site during air injection.

Geophysical tomography was used to map water saturation distributions in the subsurface; three different geophysical techniques were employed using cross-borehole techniques.

During field testing, two horizontal wells were used, including a $300-\mathrm{ft}$ injection well (165 $\mathrm{ft}$ deep, $35 \mathrm{ft}$ below the water table) and a 125-ft long extraction well (75 ft deep). Air was extracted from the upper well at a rate of $550-600 \mathrm{scfm}$ for a period of 139 days. Air injection began on day 16 at a rate of $65 \mathrm{scfm}$. On day 28, the air-injection rate was increased to 170 scfm, and on day 69 it was increased again to $270 \mathrm{scfm}$. 
Injection stopped on day 113. A total of $16,000 \mathrm{lbs}$ of VOC contamination (TCE, PCE and others) was removed through the extraction well.

Soil core samples revealed that an even larger quantity of contamination was destroyed by aerobically-activated microorganisms in the soil than was extracted by ISAS. The extraction rate of contaminant removed from the subsurface without air injection (Soil Vapor Extraction, SVE alone) was about $109 \mathrm{lb} / \mathrm{day}$, and the extraction rate increased to approximately $130 \mathrm{lb} /$ day when air was injected through the lower well.

The total cost of VOC removal for the ISAS field experiment at SRS was $\$ 15.59 / \mathrm{lb}$. In comparison, an equivalent base technology extraction system (consisting of four vertical vacuum extraction/injection wells and one pump and treat well and processing system) costs approximately $\$ 27.07 / \mathrm{lb}$ of VOC removed. Although the capital costs are higher for the ISAS system, the higher ratf of VOC removal makes it comparatively more cost effective.

\section{PROJECTED PERFORMANCE:}

ISAS performance with different geometries and/or heating and/or bioremediation nutrient injection is likely to be improved over earlier testing. Future developments will include other geometries, multiple wells, combinations of horizontal wells and vertical wells (giving hydraulic control), and orientation of horizontal injection wells perpendicular to the direction of groundwater flow. The fundamental problems for ISAS are the physical limits of volatilization and requirements of the mass transfer processes. Remaining issues are how to effectively remove the contaminant from the clays and the exponential tail recovery curves. The use of heating, steam injection, and alcohol flooding are possible options to increase volatilization in the clay zones and tight soil pores.

\section{WASTE APPLICABILITY:}

Geologic Setting. For ISAS to be effective, the geologic setting should have a moderate-to-high saturated soil permeability, homogeneous saturated zone, and sufficient saturated thickness. The vadose zone should have high permeability and homogeneity; coarse-grained soil is most effective. Clay layers have a low permeability, so they are the most difficult to remediate with air stripping.

Contaminant Requirements. Air stripping involves transport between soil, groundwater and sparged air, so contaminants must be mobile for all phases. Contaminants must have a Henry's Law constant $>0.01$, vapor pressure $>0.1 \mathrm{~mm} \mathrm{Hg}$, and soil/water partition coefficient $<1000$ in order to be physically removable by air stripping. Most light hydrocarbons and chlorinated solvents satisfy these conditions.

Plume Geometry. Horizontal wells provide better contact with linearly-shaped contaminant plumes. Thin plumes are probably more amenable to the air-stripping process. The plume depth affects the cost effectiveness of ISAS.

STATUS:

A field demonstration was performed in fiscal year 1990. A full-scale demonstration including $4 \%$ methane enhancement as a bioremediation nutrient in the injection well was conducted during 
fiscal year 1992, with results to be available in fiscal year 1993. Better under-ground transport modeling and bioremediation modeling is needed.

\section{REGULATORY CONSIDERATIONS:}

A state Underground Injection Control (UIC) permit is required due to the active injection of air into the subsurface. ISAS application requires an air permit for discharge of processed off gases at the surface. This is required to meet Clean Air Act Regulations. The demonstration work at SRS falls under the Resource Conservation and Recovery Act (RCRA) groundwater corrective action permit.

POTENTIAL COMMERCIAL APPLICATIONS:

Potential commercial applications include: remediation of leaking underground process lines, especially those where chlorinated solvents or other VOC wastes are present; and remediation of VOC contamination (or semi-volatile organic chemical contamination in some cases) where the contaminant plume has a linear geometry in the soil or where the contamination covers a large area. In remedial action applications where there is a very large volume of soil contamination, spread out over a large area at great depths, both vertical and horizontal wells could be properly used to remediate the contamination zone.

\section{BASELINE TECHNOLOGY:}

ISAS is an improvement over the vertical well SVE technology or the vertical well air-sparging technology. Broad application of ISAS is possible due to the placement of the lower injection well below the water line which can remediate both groundwater and soil in the saturated zone. Consequently, ISAS is also an improvement or alternative to a vertical well pump and treat process of groundwater remediation.

INTELLECTUAL PROPERTY RIGHTS:

U.S. patent 4660639, "Removal of Volatile Contaminants from the Vadose Zone of Contaminated Ground," was issued 28 April 1987. The vapor extraction from the upper horizontal well is covered by this patent and Westinghouse Savannah River Company has paid a one-time license with the assignee (The UpJohn Company) for the use of this process with horizontal wells. U.S. patent 4832122, "In-Situ Remediation System and Method for Contaminated Groundwater," was issued 23 May 1989. This patent is assigned to the Westinghouse Savannah River Company and DOE.

For Further Information:

DOE Program Manager

K. Gerdes; (301) 903-7289

Principle Investigator

Brian B. Looney

Westinghouse Savannah River Company

(803) 725-3692

FAX: (803) 725-7673 
References

1. Westinghouse Savannah River Company, Savannah River Site, The Savannah River Integrated Demonstration Program, WSRC-MS-91-290, No

Date.

2. Schroeder, J.D., N.D. Rosenberg, E.P. Barnes-Smith, and S.R. Booth, In-Situ Air Stripping: Cost Effectiveness of a Remediation Technology Field Tested at the Savannah River Integrated Demonstration Site, DOE 1992, LA-UR-92-1927, No Date.

3. Khandan, N.N., "Fundamentals of Mass Transfer," from Course Notes: 2nd Design Workshop for Soil and Groundwater Remediation, University of New Mexico, Nov. 1992.

4. Eddy, C.A., B.B. Looney, T.C. Hazen, D.S. Kaback, and J.L. Simmons, Post-Test Evaluation of the Geology, Geochemistry and Hydrology of the In-Situ Air Stripping Demonstration Site at the Savannah River Site, forthcoming as a Westinghouse Savannah River Report.

5. Angell, K.G., "Air Sparging, An Innovative Technique for Site Remediation," Proceedings: First Annual hazardous Materials and Environmental Management Conference, Atlanta, Georgia, pp. 92-116, Oct. 1991.

Information for this technology was provided in the May 1993 Draft of the Catalog of OTD Technologies produced by ASL, Albuquerque, NM. The Catalog of technologies is being developed for DOE/EM-521. Contacts for this project are:

Bill Noel, Program Manager

DOE/EM-521

Phone: (301) 9037900

Nancy Prindle, PI

Sandia National Laboratories

Organization 6621

Phone: (505) 844-7227

Richard Jimenez and Charlene Baca

ASL

Albuquerque, NM

Phone: (505) 828-1848

Fax: (505) 828-1952 


\section{Appendix E - Example Technology from EnviroTRADE Hydraulic Cage Technology from Germany [ET, 1993]}

Hydraulic Cage Technology

Available Technology

ER Remediation Technology for VOCs in Saturated Soil

Berlin, Germany (?)

\section{DESCRIPTION OF TECHNOLOGY:}

This technology is an engineered system to passively control geohydrological gradients over the long-term in and around a contaminated region. The cage is constructed by drilling a series of boreholes around the region in order to enhance the hydraulic conductivity of the rock between them. The boreholes can also be used for pre-construction characterization and post-construction monitoring. If properly constructed in appropriate conditions, the cage can minimize the hydraulic gradient across a site and thus effectively provide containment to advective aqueous contaminant transport.

Care must be given that the cage not exacerbate the contamination problem under certain conditions by providing a fast pathway for contaminant transport.

This technology is effective for all waste types and to deep, saturated rock sites. The technology is generally not applicable at shallow depths in dry soils where gradients are near vertical.

\section{TECHNICAL CONTACTS:}

B. Benker and H. Talmann, Consultants

Berlin, Germany

Charlie Voss

Golder Associates Inc.

4104 148th Ave NE

Redmond, WA 98052

Tel: (206) 883-0777

FAX: (206) 882-5498 
11
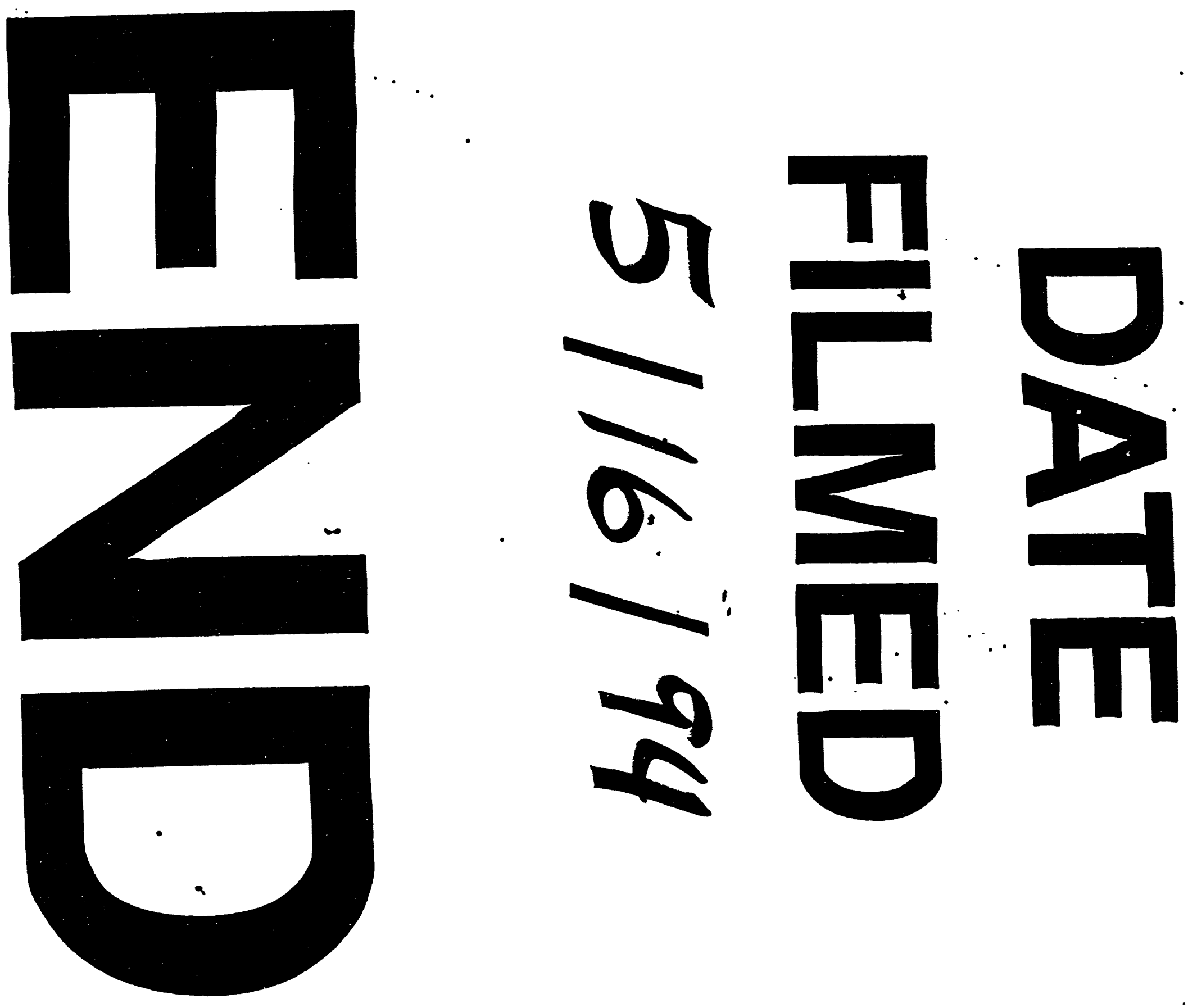
